\title{
EDITORIAL
}

\section{Safety of long-acting $\beta$-agonists: urgent need to clear the air remains}

\author{
R. Beasley*, F.D. Martinez ${ }^{\#}$, A. Hackshaw ${ }^{\uparrow,+}$, K.F. Rabe ${ }^{\S}$, P.J. Sterk ${ }^{\dagger}$ and R. Djukanovic**
}

$\mathbf{T}$ he introduction of long-acting $\beta$-agonist (LABA) drugs in the 1990s was considered a major advance in bronchodilator therapy with evidence that their use led to improved lung function and quality of life [1,2]. There were also potential safety advantages due to the twice daily, fixed dose usage, which reduced the risk of overuse of $\beta$ agonist therapy in the situation of severe exacerbations. The subsequent introduction of the combination of LABA/inhaled corticosteroid (ICS) products had the added potential value of ensuring that the patient received concomitant ICS therapy while improving compliance with ICS therapy $[3,4]$.

However, concerns about the possible risks associated with LABA therapy were raised soon after their introduction into clinical practice, with the evidence that regular LABA use had the potential to reduce bronchodilator sensitivity to $\beta$-agonists $[5,6]$ and induce tolerance to their bronchoprotective effects [7], which may not be restored by concurrent use of ICS [8]. It also became apparent that patients using LABAs may be at risk of severe exacerbations if the symptom control achieved with LABA use led to a discontinuation of ICS therapy [9]. There were also concerns about a potential risk of mortality from the Salmeterol Nationwide Surveillance Study [10]. In this UKbased study of $>25,000$ subjects, there was a nonsignificant three-fold increased risk of asthma death in subjects treated with salmeterol compared with regular salbutamol; however, there was no increase in hospital admissions or life-threatening events. This led to the USA-based Salmeterol Multicenter Asthma Research Trial (SMART), a placebo-controlled study of the safety of salmeterol in adults with unstable asthma [11]. The trial was stopped after an interim analysis of 26,000 subjects because it showed a statistically significant, four-fold increase in asthma mortality with salmeterol. Unfortunately,

\footnotetext{
*Medical Research Institute of New Zealand, Wellington, New Zealand. " Arizona Respiratory Center, University of Arizona, AZ, USA. "Cancer Research UK, and +University College London Cancer Trials Centre, London, and **Allergy and Inflammation Research, Division of Infection, Inflammation and Repair, University of Southampton, Southampton, UK. ${ }^{\S}$ Dept of Pulmonology, Leiden University Medical Centre, Leiden, and ${ }^{f}$ Dept of Respiratory Medicine, Academic Medical Centre, University of Amsterdam, Amsterdam, The Netherlands.
}

STATEMENT OF INTEREST: Statements of interest for R. Beasley, F.D. Martinez, K.F. Rabe, P.J. Sterk and R. Djukanovic can be found at www.erj.ersjournals.com/misc/statements.shtml

CORRESPONDENCE: R. Beasley, Medical Research Institute of New Zealand, PO Box 10-055, 3rd Floor, 99 The Terrace, Wellington, New Zealand. Fax: 64 44729224.E-mail: richard.beasley@mrinz.ac.nz

This manuscript has supplementary material accessible from www.erj.ersjournals.com due to low power, it was not possible to determine if the risk extended to patients receiving concomitant ICS therapy, and thus whether the risk was restricted to the use of salmeterol as monotherapy in patients with unstable asthma not receiving regular medical care. In contrast, in a large UK-based casecontrol study there was no positive association between LABAs and asthma death [12]; during the period of this study, $\sim 95 \%$ of UK asthma patients receiving LABA therapy were coprescribed ICS therapy [13].

Due to conflicting evidence, the Food and Drug Administration (FDA) confirmed the availability of both salmeterol and formoterol, but required black-box warnings on their product labels [14]. The FDA also recommended that further research was required to improve the understanding of the nature and magnitude of risk of LABA therapy. Due to the rarity of death in asthma clinical trials, one informative approach is to undertake a meta-analysis of all clinical trials of specific LABA therapy. This approach has been undertaken by SEARS et al. [15], whose meta-analysis of the risk of asthma mortality associated with formoterol is published in the current issue of the European Respiratory Journal. In their database of AstraZeneca-sponsored randomised controlled asthma trials of formoterol, there were 10 asthma-related deaths among 68,000 randomised patients. For the primary outcome variable, the risk of asthma mortality associated with formoterol treatment (Question a), the rate ratio was 1.57 (95\% confidence interval (CI) $0.31-15.1)$ and the adjusted rate ratio, controlling for trial effect, was 2.68 (95\% CI 0.53-13.5). Although these results are consistent with an increased risk of death due to asthma, the confidence intervals are wide and the differences not statistically significant. As a result, the analyses did not have enough power to detect an effect if it really exists and, importantly, there is also insufficient evidence of no harm!

The main secondary outcome variable was the relative risk of asthma mortality with formoterol administered in combination with ICS when compared with ICS alone (Question b). In our view, this analysis is more clinically relevant than the outcome in Question a because all current guidelines recommend that LABAs should only be used in combination with ICS [16-18]. This analysis identified that in patients prescribed ICS, the relative risk of asthma mortality associated with formoterol was 2.32 (95\% CI 0.30-105). While this finding suggests that concomitant use of ICS therapy may not protect against the potential risk of asthma mortality associated with formoterol (Question c), this also could not be addressed in the study in a definitive manner due to insufficient power. 
There are some methodological issues that need to be considered when interpreting the analyses by SEARS et al. [15]. First, many of the analyses are based on the total number of events and person-years across all considered trials. Essentially, this assumes that the data originate from a single study, so it does not allow for different baseline risks in different populations. It is better to combine the rate ratios from each trial, as is customary for meta-analyses. This could partly explain why the point estimate for the increase in the asthma death rate allowing for trial is higher (2.7-versus 1.6-fold). Secondly, there was an indication that among patients receiving formoterol and ICS therapy the asthma-related death rate differed according to whether there was a non-LABA comparison arm or not. In trials with a non-LABA comparison arm, the asthma death rate in patients receiving formoterol and ICS was three times greater than those without a non-LABA comparison arm (five out of 9,800 versus two out of 11,900 person-years; see supplementary data). If this bias is real it could have an effect on the rate ratio for asthma mortality, both in the overall analyses and in patients receiving baseline ICS therapy. For example, if the analysis was restricted to studies with a non-LABA comparison arm, the rate ratio for formoterol is 2.53 (95\% CI $0.45-26$; six out of 10,900 versus two out of 9,200 patient-years, see supplementary data), compared with the reported rate ratio of 1.57 . Similarly, in the analysis of subjects prescribed concomitant ICS, the rate ratio associated with formoterol plus ICS versus non-LABA plus ICS was 3.67 (95\% CI 0.41-174; five out of 9,800 versus one out of 7,200 patient-years; see supplementary data), compared with the reported rate ratio of 2.32. Therefore, the published risks of asthma mortality associated with formoterol may be underestimates of the actual risk.

Due to the low power, an important issue which could not be addressed in the analyses is whether different regimes of formoterol use were associated with differential risks. The regimes included a fixed twice daily, adjustable maintenance dose, as required use for relief of symptoms, and both maintenance and as required use, variably as separate formoterol and as combination formoterol/ICS therapy. This issue is important because the "as required for relief of symptoms" regime carries a potential risk of the overuse of formoterol in the situation of a severe attack of asthma. Conversely, the use of combination formoterol/budesonide therapy has the potential to reduce the risk, as it ensures that formoterol cannot be used as monotherapy and may lead to improved compliance with ICS therapy $[3,4]$.

A related issue which may not have received adequate consideration to date is whether the widespread use of combination ICS/LABA therapy could potentially lead to a reduction in asthma mortality through the greater use of ICS therapy. This issue cannot be addressed in randomised controlled trials, as it relates to patterns of prescribing, influenced by patient and doctor preference for combination LABA/ICS therapy over separate ICS or other therapeutic regimes. Observational data that might support this hypothesis is the gradual reduction in asthma mortality in the USA since 2000, in the setting of a marked increase in LABA use, predominantly as combination therapy $[19,20]$. During this period the two-fold increase in ICS use has been solely due to the progressive increase in the use of combination therapy, which by 2006 represented $\sim 88 \%$ of all LABA and $50 \%$ of all prescribed ICS [19]. Thus, combination LABA/ICS therapy could potentially lead to a reduction in asthma mortality through both the greater prescription of and compliance with ICS therapy.

The relative risk of mortality should be viewed in the wider safety context as intuitively one expects drugs that reduce severe exacerbations to reduce the risk of death due to asthma. The observation that hospital admissions were reduced with formoterol in this extensive clinical trial database [15] is reassuring, as hospital admissions are a recognised marker of risk of asthma mortality [21, 22]. However, as observed in the Salmeterol Nationwide Surveillance Study [10], an increased risk of asthma mortality can occur in the presence of no observed risk of hospital admissions or life-threatening attacks. The reduction in risk of hospital admissions is consistent with the Cochrane meta-analyses of the use of LABAs in conjunction with ICS therapy [23, 24], but not the meta-analysis by SALPETER et al. [25], which was dominated by the SMART study [11], suggesting once again that the circumstances in which LABA therapy is used are a determinant of risk. It is also possible that while most of the asthma population benefits from LABAs used in conjunction with ICS therapy, there is a subgroup in which the risk is increased.

So what does this study add to the current debate regarding the potential risk of asthma mortality with LABAs? The findings are not reassuring in that although they are limited by insufficient power, the data suggests that in strictly controlled randomised controlled trials formoterol may be associated with an increased risk of mortality, and that this effect might not be prevented by the concomitant administration of ICS therapy. The call for an urgent need to "clear the air" made 3 yrs ago remains [26]. This will require major commitment from the pharmaceutical industry, regulatory authorities, the medical profession and patients with asthma to undertake the required research to resolve this important issue. The priority for clinical studies would be the investigation of the risk with combination LABA/ICS therapy, which represents the preferred and most commonly used form of LABA therapy. Such studies would need to be undertaken in subjects with severe disease, the population in whom combination LABA/ICS therapy is preferentially recommended and in whom the baseline risk of mortality may be sufficiently high to detect an effect, should an effect exist. Due to the practical difficulties in undertaking randomised controlled clinical trials with adequate power to determine the risks of such a rare outcome as death from asthma, consideration will also need to be given to well-designed case-control studies. Another, and more immediate, approach would be to undertake a combined analysis of the AstraZeneca, Novartis and GlaxoSmithKline databases of formoterol and salmeterol together with the databases of other companies selling generic LABAs. We invite these pharmaceutical companies to share their databases for analysis under the leadership of the European Respiratory Society. In the meantime, we suggest that practitioners should be aware of the real safety concerns of LABA therapy, and urge them to follow current asthma guidelines that recommend the use of ICS as first line controller therapy, reserving combination therapy for subjects who are not adequately controlled with ICS therapy [16-18]. 
Finally, in conclusion we commend AstraZeneca for making its clinical trial safety database available in summary form. The data are now in the public domain and available for further analyses, as has been undertaken and published herein.

\section{REFERENCES}

1 Löfdahl CG, Chung KF. Long-acting $\beta_{2}$-adrenoceptor agonists: a new perspective in the treatment of asthma. Eur Respir J 1991; 4: 218-226.

2 Nelson HS. $\beta$-adrenergic bronchodilators. $N$ Engl J Med 1995; 333: 499-506.

3 Stempel DA, Stoloff SW, Carranza Rosenzweig JR, Stanford RH, Ryskina KL, Legorreta AP. Adherence to asthma controller medication regimens. Respir Med 2005; 99: 1263-1267.

4 Stoloff SW, Stempel DA, Meyer J, Stanford RH, Carranza Rosenzweig JR. Improved refill persistence with fluticasone propionate and salmeterol in a single inhaler compared with other controller therapies. J Allergy Clin Immunol 2004; 113: 245-251.

5 Grove A, Lipworth BJ. Bronchodilator subsensitivity to salbutamol after twice daily salmeterol in asthmatic patients. Lancet 1995; 346: 201-206.

6 Newnham DM, McDevitt DG, Lipworth BJ. Bronchodilator subsensitivity after chronic dosing with eformoterol in patients with asthma. Am J Med 1994; 97: 29-37.

7 Cheung D, Timmers MC, Zwinderman AH, Bel EH, Dijkman JH, Sterk PJ. Long-term effects of a long-acting $\beta_{2}$-adrenoceptor agonist, salmeterol, on airway hyperresponsiveness in patients with mild asthma. $N$ Engl J Med 1992; 327: 1198-1203.

8 Yates DH, Kharitonov SA, Barnes PJ. An inhaled glucocorticoid does not prevent tolerance to the bronchoprotective effect of a long-acting $\beta_{2}$-agonist. Am J Respir Crit Care Med 1996; 154: 1603-1607.

9 Arvidsson P, Larsson S, Löfdahl C-G, Melander B, Svedmyr N, Wåhlander L. Inhaled formoterol during one year in asthma: a comparison with salbutamol. Eur Respir J 1991; 4: 1168-1173.

10 Castle W, Fuller R, Hall J, Palmer J. Serevent nationwide surveillance study: comparison of salmeterol with salbutamol in asthmatic patients who require regular bronchodilator treatment. Br Med J 1993; 306: 1034-1037.

11 Nelson HS, Weiss ST, Bleecker ER, Yancey SW, Dorinsky PM, SMART Study Group. The Salmeterol Multicenter Asthma Research Trial: a comparison of usual pharmacotherapy for asthma or usual pharmacotherapy plus salmeterol. Chest 2006; 129: 15-26.

12 Anderson HR, Ayres JG, Sturdy PM, et al. Bronchodilator treatment and deaths from asthma: case-control study. BMJ 2005; 330: 117-123.
13 Maringe C, Rickard K, DiSantostefano R, Davis K, Kiri V. Concomitant use of long-acting $\beta$-agonists with inhaled corticosteroids among asthma patients in the UK primary care. Eur Respir J 2007; 30: Suppl. 51, P3698.

14 Food and Drug Administration Center for Drug Evaluation and Research. Summary Minutes of the Pulmonary-Allergy Drugs Advisory Committee. www.fda.gov/ohrms/dockets / ac/05/minutes/2005-4148M1_Final.pdf Last accessed: July 2008. Last updated: June 13, 2005.

15 Sears MR, Ottosson A, Radner F, Suissa S. Long-acting $\beta$ agonists: a review of formoterol safety data from asthma clinical trials. Eur Respir J 2009; 33: 21-32.

16 Global Initiative for Asthma. Global Strategy for Asthma Management and Prevention 2006. www.ginasthma.org/ Guidelineitem.asp??11 $=2 \& 12=1 \&$ intId $=60$ Date last accessed: November 5, 2008.

17 Bateman ED, Hurd SS, Barnes PJ, et al. Global strategy for asthma management and prevention: GINA executive summary. Eur Respir J 2008; 31: 143-178.

18 British Thoracic Society Scottish Intercollegiate Guidelines Network, British Guideline on the Management of Asthma. Thorax 2008; 63: Suppl. 4, iv1-iv121.

19 Wijesinghe M, Perrin K, Harwood M, Weatherall M, Beasley R. The risk of asthma mortality with long-acting inhaled beta-agonists. Postgrad Med J 2008; 84: 467-472.

20 Di Santostefano RL, Davis KJ, Yancey S, Crim C. Ecologic analysis of asthma-related events and dispensing of inhaled corticosteroid- and salmeterol-containing products. Ann Allergy Asthma Immunol 2008; 100: 558-565.

21 Crane J, Pearce N, Burgess C, Woodman K, Robson B, Beasley R. Markers of risk of asthma death or readmission in the 12 months following a hospital admission for asthma. Int J Epidemiol 1992; 21: 737-744.

22 Rea HH, Scragg R, Jackson R, Beaglehole R, Fenwick J, Sutherland DC. A case-control study of deaths from asthma. Thorax 1986; 41: 833-839.

23 Ni Chroinin M, Greenstone IR, Danish A, et al. Long-acting beta2-agonists versus placebo in addition to inhaled corticosteroids in children and adults with chronic asthma. Cochrane Database Syst Rev 2005; 4: CD005535.

24 Greenstone IR, Ni Chroinin MN, Masse V, et al. Combination of inhaled long-acting beta2-agonists and inhaled steroids versus higher dose of inhaled steroids in children and adults with persistent asthma. Cochrane Database Syst Rev 2005; 4: CD005533.

25 Salpeter SR, Buckley NS, Orniston TM, Salpeter EE. Metaanalysis: effect of long-acting beta-agonists on severe asthma exacerbations and asthma-related deaths. Ann Intern Med 2006; 144: 904-912.

26 Martinez FD. Safety of long-acting beta-agonists - an urgent need to clear the air. N Engl J Med 2005; 353: 2637-2639. 